\title{
ВЛИЯНИЕ ИАПФ, САРТАНОВ И ХИРУРГИЧЕСКОЙ РЕВАСКУЛЯРИЗАЦИИ НА ЖЕСТКОСТЬ СОСУДИСТОЙ СТЕНКИ У БОЛЬНЫХ ИШЕМИЧЕСКОЙ БОЛЕЗНЬЮ СЕРДЦА В СОЧЕТАНИИ С ХРОНИЧЕСКОЙ БОЛЕЗНЬЮ ПОЧЕК
}

\author{
() Яковлева М.В. ${ }^{2}$, Прибылов С.А. ${ }^{1}$, Прибылова Н.H. ${ }^{1}$ \\ ${ }^{1}$ Курский государственный медицинский университет (КГМУ) \\ Россия, 305041, Курская область, г. Курск, ул. К. Маркса, д. 3 \\ ${ }^{2}$ Курская городская клиническая больница скорой медицинской помощи (КГКБ СМП) \\ Россия, 305047, Курская область, г. Курск, ул. Пирогова, д. 14
}

На долю ишемической болезни сердца (ИБС) приходится 50\% всех сердечно-сосудистых исходов у больных со сниженной скоростью почечной фильтрации. Говоря о этиопатогенезе коморбидной патологии, можно утверждать, что жесткость сосудистой стенки является общим знаменателем при сочетании ИБС с хронической болезнью почек (ХБП).

Цель исследования: определить исходный уровень показателей жесткости сосудистой стенки у пациентов с хроническими формами ИБС в сочетании с ХБП 1-3 степени, а также эластичность сосудистой стенки на фоне комплексной терапии ИБС, включающей иАПФ или сартаны.

Материалы и методы. Обследовано 74 пациента с хроническими формами ИБС, стабильной стенокардией напряжения I-III ФК в сочетании с ХБП 1-3 степени. Региональную жесткость артерий оценивали с помощью объемной сфигмографии прибором VS-1500 (Fucuda Denshi, Япония).

Результаты. У пациентов с ИБС в сочетании с ХБП имеет место значимое увеличение скорости распространения пульсовой волны (СРПВ), повышение индекса аугментации. На фоне лечения во всех группах имела место тенденция к нормализации показателей жесткости сосудистой стенки. Наиболее наглядно это видно при изучении СРПВ и СЛСИ. При консервативной терапии с применением иАПФ за 12 недель наблюдения произошло уменьшение СРПВ на 2,3\% , в группе, где проводилась хирургическая реваскуляризация миокарда, - на 5,4\%, а при применении сартанов - на $15,7 \%(\mathrm{p}<0,05)$.

Заключение. Определение параметров артериальной жесткости, а именно СЛСИ и СРПВ, может использоваться как объективный маркер контроля эффективности терапии у пациентов с ИБС в сочетании с ХБП. Проведение реваскуляризации миокарда посредством стентирования коронарных артерий приводит к нормализации показателей жесткости сосудистой стенки в большей мере, чем консервативная тактика. Сартаны за 12 недель продемонстрировали достоверно более благоприятное воздействие на жесткость сосудистой стенки у пациентов с коморбидной патологией, чем иАПФ, при прочих равных условиях.

Ключевые слова: ишемическая болезнь сердца; хроническая болезнь почек; жесткость сосудистой стенки; иАПФ; сартаны; реваскуляризация миокарда.

Яковлева Маргарита Валерьевна - врач-кардиолог, КГКБ СMП, г. Курск. ORCID iD: 0000-0001-8820-6182. E-mail: ya.yakovlevamargarita@yandex.ru (автор, ответственный за переписку)

Прибылов Сергей Александрович - д-р мед. наук, профессор, зав. кафедрой внутренних болезней ФПО, КГМУ, г. Курск. E-mail: vbfpo@mail.ru

Прибылова Надежда Николаевна - д-р мед. наук, профессор, профессор кафедры внутренних болезней ФПО, КГМУ, г. Курск. E-mail: pribylova nadezda@mail.ru

По прогнозам ученых, эпидемия болезней системы кровообращения в развитых странах мира продолжит набирать обороты, и к 2030 г. распространенность ИБС увеличится на 9,3\% [10]. В связи с этим ишемическая болезнь сердца (ИБС) остается главной причиной смертности и инвалидизации населения. Эффективность лечения ряда соматических заболеваний и вторичная профилактика поражения органовмишеней привели к сокращению числа фатальных осложнений, в том числе обусловленных поражением почек. Это привело к увеличению числа больных с различной степенью хронической болезни почек (ХБП).

В частности, исследование скорости клубочковой фильтрации (СКФ) 31914 пациентов с артериальной гипертензией с одним или несколь- кими факторами сердечно-сосудистого риска показало, что ИБС чаще всего встречается у лиц с низкой (менее 60 мл/мин) и умеренной СКФ (60-89 мл/мин) [6].

В настоящее время ИБС остается главной причиной смерти среди пациентов с хронической болезнью почек (ХБП). На ее долю приходится $50 \%$ всех сердечно-сосудистых исходов у больных со сниженной СПФ [3].

ИБС и ХБП - два серьезных заболевания, прогрессирование которых взаимоутяжеляет их течение. С целью отражения взаимодействия кардиальной и почечной патологии была предложена концепция кардиоренального синдрома [2].

Снижение функции почек по мере прогрессирования ХБП способствует развитию атеро- 
склероза. В свою очередь, нарастание выраженности последнего приводит к дальнейшему прогрессированию и усилению нарушений со стороны клубочкового аппарата почек. При этом артериальная гипертензия (АГ) может выступать как фактором риска появления, так и причиной, усугубляющей имеющиеся нарушения клубочковой фильтрации [9].

Одним из критериев, характеризующих ремоделирование сосудистой стенки, является ее эластичность, нарушение которой служит важным звеном в патогенезе коронарного атеросклероза [7].

Жесткость сосудистой стенки - важное звено патогенеза развития ишемии миокарда [3, 5]. Установлено, что наличие почечной патологии и снижение скорости клубочковой фильтрации ассоциируется с увеличением жесткости сосудистой стенки. Повышение артериальной ригидности является отличительным признаком ХБП [5]. В доступной литературе последних лет мы не встретили работ, посвященных влиянию реваскуляризации миокарда и фармакотерапии ИБС.

Имеющиеся рекомендации по профилактике и лечению сердечно-сосудистых заболеваний базируются на возможности и степени коррекции модифицируемых факторов риска, таких как дислипидемия и гипертония. В то же время характер и степень нарушения клубочковой фильтрации не фигурируют в качестве параметров для оценки степени сердечно-сосудистого риска даже в Фремингемской шкале и EURO SCORE, разработанных с целью планирования первичных профилактических мероприятий.

Учитывая, что сартаны и иАПФ оказывают ангио- и нефропротективное воздействие, а также широко используются для лечения ИБС $[4,14]$, хронической сердечной недостаточности (XCH), можно ожидать синергизм указанных препаратов с лекарственными средствами, улучшающими коронарный кровоток, либо с чрескожным коронарным вмешательством (ЧКВ), несомненно влияющим на кровоснабжение миокарда, на функциональную активность левого желудочка.

Имеются отдельные работы, описывающие эффекты терапии ИБС, прежде всего острых форм, у пациентов с нарушениями почечной функции. Тем не менее остается неясным отношение к стентированию коронарных артерий при сочетании хронических форм ИБС и ХБП $[4,8,10,12]$.

Цель исследования: определить исходный уровень показателей жесткости сосудистой стенки у пациентов с хроническими формами ИБС в сочетании с ХБП 1-3 степени, а также эластичность сосудистой стенки на фоне ком- плексной терапии ИБС, включающей иАПФ или сартаны.

\section{МАТЕРИАЛЫ И МЕТОДЫ ИССЛЕДОВАНИЯ}

В исследование включено 74 пациента с хроническими формами ИБС (постинфарктным кардиосклерозом (инфаркт миокарда в анамнезе менее года до начала исследования), стабильной стенокардией напряжения I-III ФК (документированная госпитализация по поводу нестабильности коронарного кровотока в течение предшествующих 6 месяцев до начала исследования) в сочетании с ХБП 1-3 степени. Длительность наблюдения составила 12 недель.

ХБП 1-3 степени выявлена ранее, амбулаторно за 5-7 лет до госпитализации, и подтверждена расчетом СКФ по формуле MDRD при поступлении. Генез ХБП у всех обследуемых пациентов представлен гипертонической нефропатией. Длительность артериальной гипертензии у обследуемых составила 8 лет и более. Согласно анализу информации из амбулаторной карты, $77,8 \%$ больных имели АГ 3 степени и лишь $22,2 \%$ - 2 степени.

Критериями включения в исследование являлись: возраст больных от 40 до 75 лет; физическая и умственная способность к участию в исследовании; наличие в анамнезе подтвержденной ИБС (положительный тредмил тест, наличие документированного инфаркта миокарда в анамнезе более 2 месяцев до момента госпитализации и менее 1 года, результаты ранее проеденной коронароангиографии), ХБП 1-3 степени в анамнезе и при поступлении.

Критерии исключения: ожирение, сахарный диабет, острые воспалительные заболевания почек, тяжелая сопутствующая патология, способная оказать самостоятельное влияние на прогноз, отсутствие приверженности к назначенной терапии в течение 12 недель исследования, наличие событий, требующих коррекции терапии в течение 12 недель исследования.

Bсе пациенты получали дезагрегантную терапию (кардиомагнил 75 мг/сутки и клопидогрель 75 мг/сутки), статины (аторвастатин 40 мг/сутки), $\beta$-адреноблокаторы (бисопролол 2,5-5 мг/сутки). Пациенты разделены на три группы. В первую вошли больные ИБС в сочетании с ХБП 1-3 степени, получающие в дополнение к традиционной фармакотерапии иАПФ (периндоприл в дозе 5-10 мг 1 раз в сутки или лизиноприл в дозе 5-10 мг 1 раз в сутки), во вторую - получающие сартаны вследствие непереносимости иАПФ (лозартан 100 мг 1 раз в сутки). Назначение лозартана в указанной дозировке происходило на 1-2-е сутки исследования. 
Исходное состояние жесткости сосудистой стенки у больных ИБС в сочетании с ХБП 1-3 степени Initial state of vascular wall stiffness in patients with $\mathrm{CHD}$ in combination with 1-3 degree CKD

\begin{tabular}{|c|c|c|c|}
\hline \multirow{2}{*}{$\begin{array}{l}\text { Показатель } \\
\text { Index }\end{array}$} & \multicolumn{3}{|c|}{$\begin{array}{c}\text { ИБС на фоне ХБП 1-3 ст. } \\
\text { IHD in combination with 1-3 degree CКD }\end{array}$} \\
\hline & $\begin{array}{c}\text { Группа } 1(\mathrm{n}=35) \\
\text { Group } 1(\mathrm{n}=35)\end{array}$ & $\begin{array}{c}\text { Группа } 2(\mathrm{n}=15) \\
\text { Group } 2(\mathrm{n}=15)\end{array}$ & $\begin{array}{c}\text { Группа } 3(\mathrm{n}=24) \\
\text { Group } 3(\mathrm{n}=24)\end{array}$ \\
\hline $\begin{array}{l}\text { Креатинин, мкмоль/л } \\
\text { Creatinine, } \mu \text { mol/l }\end{array}$ & $128 \pm 32$ & $118 \pm 17$ & $123 \pm 21$ \\
\hline $\begin{array}{l}\text { СКФ, мл/мин/1,73м }{ }^{2} \\
\mathrm{GFR}, \mathrm{mL} / \mathrm{min} / 1.73 \mathrm{~m}^{2}\end{array}$ & $51 \pm 5.3$ & $56 \pm 4.73$ & $53 \pm 6.2$ \\
\hline $\begin{array}{l}\text { ИМТ } \\
\text { BMI }\end{array}$ & $24.5 \pm 2.4$ & $25.0 \pm 2.3$ & $23.1 \pm 1.8$ \\
\hline $\begin{array}{l}\text { СРПВ, } \mathrm{m} / \mathrm{c} \\
\mathrm{PWV}, \mathrm{m} / \mathrm{s}\end{array}$ & $9.90 \pm 0.21$ & $9.93 \pm 0.18$ & $9.95 \pm 0.18$ \\
\hline $\mathrm{AI}$ & $1.23 \pm 0.14$ & $1.23 \pm 0.12$ & $1.23 \pm 0.11$ \\
\hline R-CAVI & $9.94 \pm 0.81$ & $9.93 \pm 0.83$ & $9.92 \pm 0.76$ \\
\hline L-CAVI & $9.82 \pm 0.7$ & $9.76 \pm 0.71$ & $9.77 \pm 0.83$ \\
\hline R-ABI & $1.14 \pm 0.18$ & $1.14 \pm 0.16$ & $1.14 \pm 0.16$ \\
\hline L-ABI & $1.14 \pm 0.15$ & $1.14 \pm 0.13$ & $1.14 \pm 0.13$ \\
\hline
\end{tabular}

Примечание: здесь и в таблице 2 данные представлены в виде $\mathrm{M} \pm \mathrm{SD}$, СРПВ - скорость пульсовой волны на аорте, AI - индекс аугментации в аорте; CAVI - сердечно-лодыжечный сосудистый индекс, ABI - лодыжечно-плечевой индекс давления, ИМТ - индекс массы тела.

Note: here and in table 2 the data are presented as $\mathrm{M} \pm \mathrm{SD}, \mathrm{CKD}$ - chronic kidney disease, CHD - Coronary heart disease, GFR - glomerular filtration rate, PWV - pulse wave velocity, AI - augmentation index, CAVI - cardio-ankle vascular index, $\mathrm{ABI}$ - ankle-brachial index, BMI - body mass index.

В первую группу (n=35) вошли 21 мужчина и 14 женщин, средний возраст которых составил $67 \pm 4,8$ года. Вторую группу составили 15 пациентов (8 мужчин и 7 женщин), средний возраст - $65 \pm 4,8$ года.

Третью группу составили пациенты, направленные на плановое проведение ЧКВ. В нее вошли 24 пациента (14 мужчин, 10 женщин), получающие традиционную терапию, а также иАПФ (периндоприл в дозе 5-10 мг 1 раз в сутки или лизиноприл в дозе 5-10 мг 1 раз в сутки), которым на 2-е сутки исследования было проведено стентирование гемодинамически значимых стенозов коронарных артерий. Средний

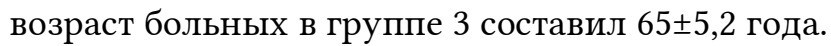

Лабораторное и инструментальное обследование по протоколу выполнялось в 1-й день и через 12 недель от начала исследования.

На каждого пациента заполнялась индивидуальная карта пациента, включающая антропометрические данные, сведения медицинского анамнеза, назначавшихся лекарственных препаратов, а также результатов лабораторноинструментального обследования (общий анализ крови, общий анализ мочи, определение концентрации альбумина, креатинина, общего холестерина и его фракций, ЭКГ, УЗИ почек).
Региональную жесткость сосудистой стенки изучали с помощью объемной сфигмографии. Показатели получали с помощью прибора VS-1500 (Fucuda Denshi, Япония). Определяли следующие показатели, характеризующие артериальную ригидность [6, 8]: скорость распространения пульсовой волны (СРПВ), сердечнолодыжечный сосудистый индекс (СЛСИ/CAVI), лодыжечно-плечевой индекс давления, индекс аугментации.

Все определяемые количественные показатели, а также паспортную часть вносили в базы данных с использованием прикладных программ Microsoft Excel из пакета Microsoft Office 2010 с расчетом средней величины и стандартного отклонения $(\mathrm{M} \pm \mathrm{SD})$, для анализа рассчитывали параметрический критерий $\mathrm{t}$ Стьюдента. Статистически значимым считали $\mathrm{p}<0,05$. Для подтверждения нормальности распределения определяли W-критерий Шапиро-Уилка в программе SPSS Statistica 6.0.

\section{РЕЗУЛЬТАТЫ ИССЛЕДОВАНИЯ И ИХ ОБСУЖДЕНИЕ}

При изучении показателей эластичности сосудистой стенки (таблица 1) достоверной зна- 
чимости по изучаемым показателям исходно между группами выявлено не было.

Согласно данным литературы СРПВ рассматривается как предиктор развития сердечнососудистых событий. Одновременно с этим ученые также связывают увеличение данного параметра жесткости сосудистой стенки с вероятностью прогрессирования ХБП [11]. При этом по отношению к пациентам с мягкой и умеренной ХБП также справедливо утверждение, что более высокие уровни СРПВ связаны с более выраженным снижением функции почек у пациентов с ХБП [13]. Результаты нашего исследования еще раз демонстрируют и подтверждают эту закономерность, в том числе и для пациентов с сочетанием ИБС и ХБП 1-3 степени.
Через 12 недель проводили повторную оценку параметров артериальной жесткости (таблица 2).

Таким образом, из полученных результатов видно, что на фоне лечения во всех трех группах имела место тенденция к нормализации показателей жесткости сосудистой стенки. Наиболее наглядно это видно при изучении СРПВ и СЛСИ. Так, при консервативной терапии с применением иАПФ (группа 1) за 12 недель наблюдения произошло уменьшение СРПВ на 2,3\% (рис. 1), в группе 3 - на 5,4\%, а при применении сартанов (группа 2) - на 15,7\% (достоверная значимость $\mathrm{p}<0,05)$. В литературе не встречается анализа эффективности лечения пациентов с хроническими формами ИБС в сочетании

Таблица 2

Table 2

Динамика показателей, отражающих состояние жесткости сосудистой стенки у больных ИБС в сочетании с ХБП 1-3 степени на фоне лечения через 12 недель

Dynamics of vascular wall stiffness indicators in patients with CHD in combination with 1-3 degree CKD after 12 weeks of treatment

\begin{tabular}{|c|c|c|c|}
\hline \multirow{2}{*}{$\begin{array}{c}\text { Показатель } \\
\text { Index }\end{array}$} & \multicolumn{3}{|c|}{$\begin{array}{c}\text { ИБС на фоне ХБП 1-3 ст. } \\
\text { CHD in combination with 1-3 degree CKD }\end{array}$} \\
\cline { 2 - 4 } & $\begin{array}{c}\text { Группа 1 }(\mathrm{n}=35) \\
\text { Group 1 }(\mathrm{n}=35)\end{array}$ & $\begin{array}{c}\text { Группа 2 (n=15) } \\
\text { Group 2 }(\mathrm{n}=15)\end{array}$ & $\begin{array}{c}\text { Группа 3 }(\mathrm{n}=24) \\
\text { Group 3 (n=24) }\end{array}$ \\
\hline $\begin{array}{c}\text { CPПB, M/c } \\
\text { PWV, m/s }\end{array}$ & $9.67 \pm 0.14$ & $8.37 \pm 0.21^{*}$ & $9.41 \pm 0.14^{*}$ \\
\hline AI & $1.12 \pm 0.13$ & $1.08 \pm 0.12$ & $1.12 \pm 0.13$ \\
\hline R-CAVI & $9.67 \pm 0.79$ & $9.06 \pm 0.58^{*}$ & $9.31 \pm 0.81^{*}$ \\
\hline L-CAVI & $9.58 \pm 0.8$ & $8.99 \pm 0.74^{*}$ & $9.29 \pm 0.8^{*}$ \\
\hline R-ABI & $1.01 \pm 0.06$ & $1.03 \pm 0.12$ & $1.09 \pm 0.07$ \\
\hline L-ABI & $1.07 \pm 0.18$ & $1.04 \pm 0.16$ & $1.08 \pm 0.15$ \\
\hline
\end{tabular}

Примечание: * - р<0,05 при сравнении пациентов групп 2 и 3 с больными ИБС и ХБП 1-3 степени, получающими традиционную фармакотерапию, включающую иАПФ.

Note: ${ }^{*}-\mathrm{p}<0.05$ reliability as compared groups 2 and 3 patients to patients with $\mathrm{CHD}$ and $\mathrm{CKD}$ of $1-3$ degrees, receiving traditional pharmacotherapy, including inhibitors of angiotensin-converting enzyme.

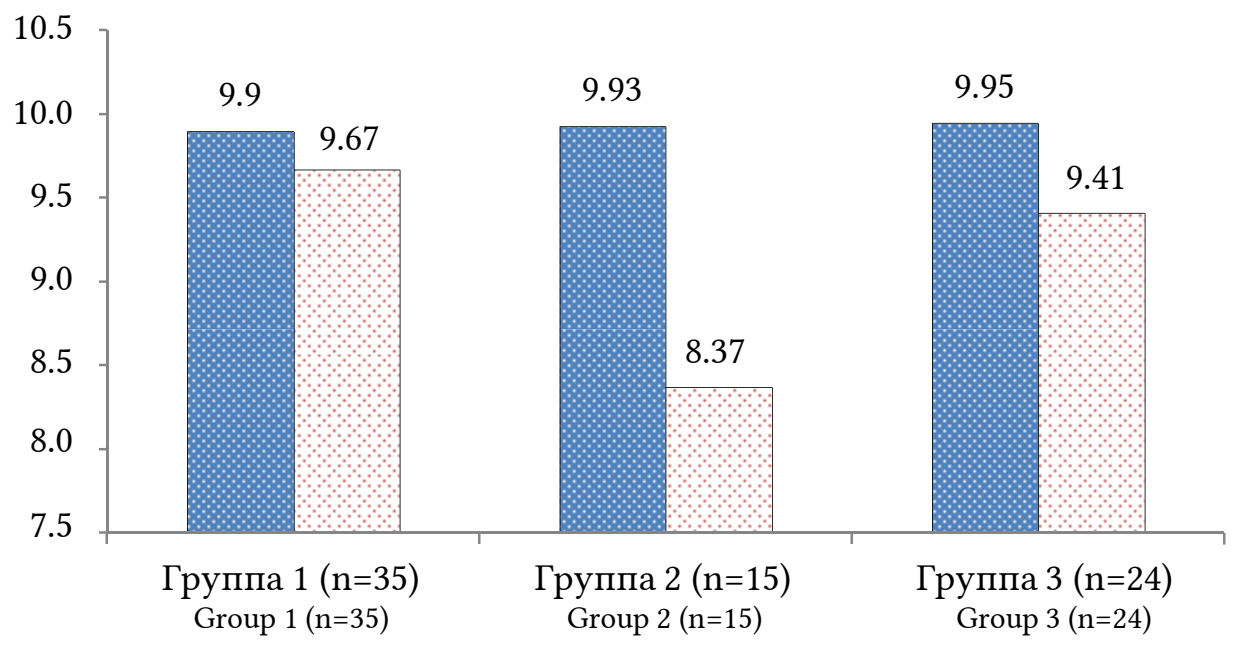

Рис. 1. Динамика СРПВ в зависимости от вида терапии.

Fig. 1. Dynamics of pulse wave velocity depending on the type of therapy. 


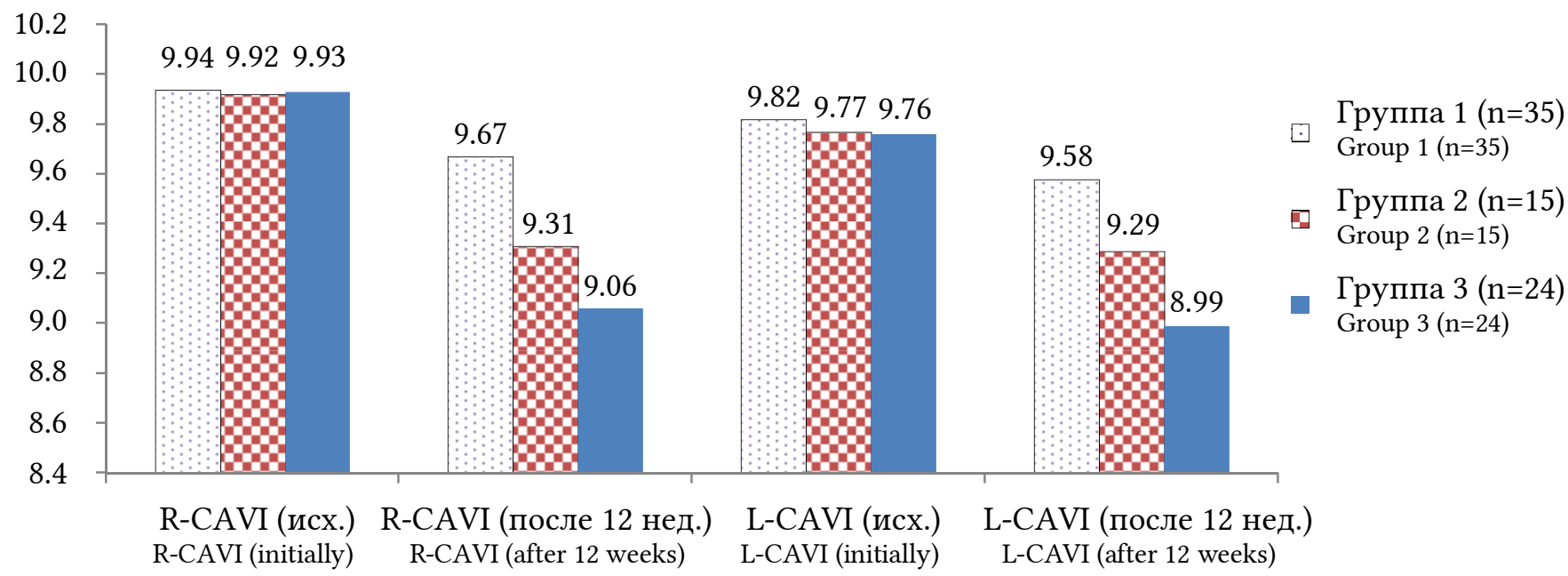

Рис. 2. Динамика СЛСИ в зависимости от вида терапии.

Примечание: группа 1 - пациенты, получающие консервативную терапию с применением иАПФ на протяжении всего исследования; группа 2 - пациенты, получающие консервативную терапию на протяжении всего исследования, которым была проведена хирургическая реваскуляризация миокарда; группа 3 - пациенты, получающие консервативную терапию с применением сартанов на протяжении всего исследования.

Fig. 2. The dynamics of CAVI depending on the type of therapy.

Note: group 1 - patients receiving conservative therapy with angiotensin-converting enzyme inhibitors throughout the study; group 2 - patients receiving conservative therapy throughout the study who underwent surgical myocardial revascularization; group 3 patients receiving conservative therapy with the use of sartans throughout the study.

с ХБП, в том числе и коронарного стентирования, с использованием оценки параметров жесткости сосудистой стенки. Имеются лишь отдельные данные по эффективности той или иной группы препаратов при коморбидной патологии или же изучаются острые формы ИБС на фоне снижения почечной функции.

Например, ранее в многочисленных исследованиях доказана эффективность и безопасность сартанов. Изучено влияние на прогноз у пациентов группы высокого риска, где выявлена эквивалентность действия сартанов и ингибиторов ангиотензинпревращающего фермента (иАПФ) по влиянию на риск сердечнососудистой смерти, инфаркта миокарда, инсульта и госпитализации в связи с сердечной недостаточностью [8].

При анализе динамики СЛСИ зарегистрировано уменьшение R-CAVI и L-CAVI - на 2,7\% и $3,6 \%$ соответственно в первой группе. В группе 3 R-CAVI и L-CAVI снизились на $6,1 \%$ и $4,9 \%$ соответственно (достоверная значимость $\mathrm{p}<0,05$ ). В группе 2 к 12-й неделе исследования тенденция к нормализации СЛСИ происходила со скоростью 8,8\% для R-CAVI и 7,9\% для L-CAVI (рис. 2).

B нашем исследовании, при изучении жесткости сосудистой стенки, наиболее выраженные позитивные изменения параметров артериальной ригидности регистрировались в группе 2. Это позволяет предположить более благоприятное воздействие именно сартанов у пациентов с коморбидной патологией (ИБС в сочетании с
ХБП), а также их видимое преимущество перед фармакотерапией, включающей иАПФ, при прочих равных условиях у данных больных.

При использовании в комплексной терапии ИБС иАПФ и после хирургической реваскуляризации сердца в виде стентирования коронарных артерий впервые показано, что через 12 недель лечения снижаются показатели жесткости сосудистой стенки (СРПВ, СЛСИ, индекс аугментации) у больных ИБС в сочетании с ХБП 1-3 степени в большей мере, нежели при фармакотерапии, включающей иАПФ. При этом мы не зарегистрировали отрицательного влияния ЧКВ на функцию почек. При изучении почечной фильтрации установлено, что через 12 недель исследования уровень креатинина в группе 1 снизил-

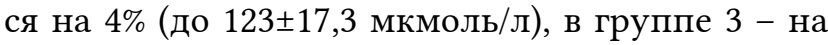
$6,5 \%$ и составил через 12 недель $115 \pm 16,7$ мкмоль/л. Сочетание медикаментозной терапии с применением иАПФ и коронарного стентирования в нашем исследовании показало отсутствие негативного влияния ЧКВ на клубочковую фильтрацию.

Таким образом, у коморбидных пациентов (ИБС и ХБП) имеет место повышение параметров жесткости сосудистой стенки, наиболее диагностически значимыми из которых являются СЛСИ и СРПВ. При консервативной тактике лечения с применением иАПФ хронических форм ИБС у пациентов с ХБП 1-3 степени отмечается достоверное снижение исходно высоких значений артериальной ригидности. Вместе с тем 
проведение реваскуляризации миокарда посредством стентирования коронарных артерий с гемодинамически значимыми стенозами таким больным приводит к нормализации показателей жесткости сосудистой стенки в большей мере, чем консервативная тактика $(\mathrm{p}<0,05)$. В то же время эффективной в отношении коррекции параметров артериальной жесткости показала себя и консервативная терапия с использованием сартанов, что позволяет предположить наиболее благоприятное, в сравнении с иАПФ, воздействие препаратов этой группы у пациентов с коморбидной патологией (ИБС в сочетании с ХБП).

\section{КОНФЛИКТ ИНТЕРЕСОВ}

Авторы декларируют отсутствие явных и потенциальных конфликтов интересов, связанных с публикацией настоящей статьи.

\section{ИСТОЧНИКИ ФИНАНСИРОВАНИЯ}

Исследование проводилось на базах кардиологического отделения БМУ КОКБ, кардиологического отделения КГКБ СМП, ФБГОУ ВО КГМУ. Дополнительные источники финансирования в исследование не привлекались.

\section{СООТВЕТСТВИЕ ПРИНЦИПАМ ЭТИКИ}

Протокол исследования одобрен Региональным этическим комитетом при Курском государственном медицинском университете (протокол № 7 от 07.09.2015 г.), каждый из испытуемых подписывал информированное согласие на участие в исследовании.

\section{ЛИТЕРАТУРА/REFERENCES}

1. Белялов Ф.И. Лечение болезней в условиях коморбидности. 10-е издание. Москва: ГЭОТАР-Медиа, 2016. 512 c. [Belyalov F.I. Treatment of diseases in conditions of comorbidity. $10^{\text {th }}$ edition. Moscow: GEOTAR-Media, 2016. 512 p. (in Russ.)]

2. Визир В.А., Березин А.Е. Кардиоренальный синдром. Артериальная гипертензия. 2011; 2(16):100109 [Vizir V.A., Berezin A.E. Cardiorenal syndrome. Arterial'naya gipertenziya. 2011; 2(16):100-109 (in Russ.)]

3. Гурфинкель Ю.И., Каце Н.В., Парфенова Л.И., Иванова И.Ю., Орлов В.А. Сравнительное исследование скорости распространения пульсовой волны и эндотелиальной функции у здоровых и пациентов с сердечно-сосудистой патологией. Российский кардиологический журнал. 2009; 14(2):38-43 [Gurfinkel Yu.I., Katse N.V., Parfenova L.M., Ivanova I.Yu., Orlov V.A. Pulse wave velocity and endothelial function comparison in healthy people and cardiovascular patients. Russian fournal of Cardiology. 2009; 14(2):38-43 (in Russ.)] DOI: 10.15829/1560-4071-2009-2-38-43

4. Кириченко А.А. Сартаны и проблема коморбидности. Русский медищинский журнал. 2018;
26(1-2):110-114 [Kirichenko A.A. Sartans and the problem of comorbidity. Russkiy meditsinskiy zhurnal. 2018; 26(1-2):110-114 (in Russ.)]

5. Кочкина М.С., Затейщиков Д.А., Сидоренко Б.А. Измерение жесткости артерий и ее клиническое значение. Кардиология. 2005; 45(1):64-72 [Kochkina M.S., Zatcyshchikov A.A., Sidorenko B.A. Measurement of arterial stiffness and its clinical value. Kardiologiya. 2005; 45(1):64-72 (in Russ.)]

6. Милягин В.А., Комиссаров В.Б. Современные методы определения жесткости сосудов. Артериальная гипертензия. 2010; 16(2):134-143 [Milyagin V.A., Komissarov V.B. Modern methods of evaluation of vascular stiffness. Arterialnaya gipertenziya. 2010; 16(2):134-143 (in Russ.)]

7. Назарова О.А., Назаров А.В. Поражение сосудов при артериальной гипертензии. Вестник Ивановской медицинской академии. 2012; 17(2):60-66 [Nazarova O.A., Nazarova A.V. Vascular lesion in arterial hypertension. Bulletin of the Ivanovo state medical academy. 2012; 17(2):60-66 (in Russ.)]

8. Недогода С.В., Чаляби Т.А. Сосудистая жесткость и скорость распространения пульсовой волны: новые факторы риска сердечно-сосудистых осложнений и мишени для фармакотерапии. Болезни сердиа и сосудов. Приложение к журналу Consilium Medicum. 2006; (4):34-42 [Nedogoda S.V., Chalyabi T.A. Vascular rigidity and pulse wave propagation rate: new risk factors for cardiovascular complications and pharmacotherapy targets. Bolezni serdtsa $i$ sosudov. Prilozheniye $k$ zhurnalu Consilium Medicum. 2006; (4):34-42 (in Russ.)]

9. Смирнов А.В., Есаян А.М., Каюков И.Г., Кучер А.Г., Добронравов В.А., Тугушева Ф.А. Современные подходы к замедлению прогрессирования хронической болезни почек. Нефрология. 2004; 8(3):89-99 [Smirnov A.V., Essaian A.M., Kayukov I.G., Kucher A.G., Dobronravov V.A., Tugusheva F.A. Current approaches to retarded progression of chronic kidney disease. Nefrologiya. 2004; 8(3):89-99 (in Russ.)]

10. Heidenreich P.A., Trogdon J.G., Khavjou O.A., Butler J., Dracup K., Ezekowitz M.D., Finkelstein E.A., Hong Y. et al. Forecasting the future of cardiovascular disease in the United States: a policy statement from the American Heart Association. Circulation. 2011; 123(8):933-944.

DOI: 10.1161/CIR.0b013e31820a55f5.

11. Liu I.T., Wu J.S., Yang Y.C., Huang Y.H., Lu F.H., Chang C.J. Mild chronic kidney disease associated with greater risk of arterial stiffness in elderly adults. f Am Geriatr Soc. 2013; 61(10):1758-1762. DOI: $10.1111 /$ jgs.12445.

12. ONTARGET Investigators, Yusuf S., Teo K.K., Pogue J., Dyal L., Copland I., Schumacher H., Dagenais G. et al. Telmisartan, ramipril, or both in patients at high risk for vascular events. $N$ Engl f Med. 2008; 358(15):1547-1559. DOI: 10.1056/NEJMoa0801317

13. Sengstock D., Sands R.L., Gillespie B.W., Zhang X., Kiser M., Eisele G., Vaitkevicius P., Kuhlmann M. et al. Dominance of traditional cardiovascular risk factors over renal function in predicting arterial stiff- 
ness in subjects with chronic kidney disease. Nephrol Dial Transplant. 2010; 25(3):853-861. DOI: $10.1093 / \mathrm{ndt} / \mathrm{gfp} 559$

14. Uechi Y., Sunagawa O., Ishikawa N., Inoue T., Tamashiro M., Kamiyama T., Suzuki T. et al. Risk factors for stiffness of the wall of the thoracic aorta in patients with mild atherosis. Jpn Circ J. 2001; 65(5):409413. DOI: $10.1253 /$ jcj.65.409

Поступила в редакцию 03.06.2019

Подписана в печать 19.09.2019

Для цитирования: Яковлева М.В., Прибылов С.А., Прибылова Н.Н. Влияние иАПФ, сартанов и хирургической реваскуляризации на жесткость сосудистой стенки у больных ишемической болезнью сердца в сочетании с хронической болезнью почек. Курский научно-практический вестник «Человек и его здоровье». 2019; (3):12-19. DOI: 10.21626/vestnik/2019-3/02.

INFLUENCE OF INHIBITORS OF ANGIOTENSIN-CONVERTING ENZYME, SARTAN AND SURGICAL REVASCULARIZATION ON VASCULAR WALL STIFFNESS IN PATIENTS WITH CORONARY HEART DISEASE IN COMBINATION WITH CHRONIC KIDNEY DISEASE

\author{
○ Yakovleva M.V. ${ }^{2}$, Pribylov S.A. ${ }^{1}$, Pribylova N.N. ${ }^{1}$ \\ ${ }^{1}$ Kursk State Medical University (KSMU) \\ 3, K. Marx St., Kursk, Kursk region, 305041, Russian Federation \\ ${ }^{2}$ Kursk City Clinical Hospital of Emergency Medical Care (KCCH EMC) \\ 14, Pirigov St., Kursk, Kursk region, 305047, Russian Federation
}

$50 \%$ of all cardiovascular outcomes in patients with chronic kidney disease (CKD) fall into the share of coronary heart disease (CHD). The vascular wall stiffness is a common denominator when combined coronary heart disease and CKD.

Objective: determination of initial level of indicators of vascular wall stiffness in patients with chronic forms of CHD in combination with CKD of 1-3 degrees and also their dynamic control with different therapeutic approaches.

Materials and methods. 74 patients with chronic forms of CHD, I-III functional classes stable angina in combination with CKD of 1-3 degrees are examined. The regional stiffness of arteries was estimated by volumetric sphygmography by means of the VS-1500 device (Fucuda Denshi, Japan).

Results. Patients with coronary heart disease in combination with CKD develop a significant increase in pulse wave velocityand an increase in the augmentation index. Against the background of treatment all groups tend to normalize the indicators of vascular wall stiffness. It is most clearly seen when studying pulse wave velocity and CAVI. The conservative therapy with inhibitors of angiotensin-converting enzyme contributed to reducting pulse wave velocity by $2.3 \%$ within 12 weeks of observation; in the group with surgical revascularization of myocardium - by 5.4\%; and in using sartan - by $15.7 \%$ (p $<0.05$ ).

Conclusion. Determination of parameters of arterial stiffness, namely, speed of pulse wave velocity and CAVI, can be used as an objective marker for monitoring the efficiency of therapy in patients with coronary heart disease in combination with CKD. Carrying out revascularization of myocardium through stenting coronary arteries leads to normalization of stiffness indicators of the vascular wall to a greater extent than conservative tactics. Sartan within 12 weeks showed a significantly more favorable effect on the stiffness of the vascular wall in patients with comorbid pathology, than inhibitors of angiotensin-converting enzyme with other things being equal.

Keywords: coronary heart disease; chronic disease of kidneys; stiffness of a vascular wall; influence of inhibitors of angiotensin-converting enzyme; sartan; myocardium revascularization.

Yakovleva Margarita V. - Cardiologist, KCCH EMC, Kursk, Russian Federation. ORCID iD: 0000-0001-8820-6182. E-mail: ya.yakovlevamargarita@yandex.ru (correspondence author)

Pribylov Sergey A. - DM, Professor, Head of Department of Internal Diseases of Postgraduate Education Faculty, KSMU, Kursk, Russian Federation. E-mail: vbfpo@mail.ru

Pribylova Nadezhda N. - DM, Professor, Professor of Department of Internal Diseases of Postgraduate Education Faculty, KSMU, Kursk, Russian Federation. E-mail: pribylova nadezda@mail.ru

\section{CONFLICT OF INTEREST}

The authors declare the absence of obvious and potential conflicts of interest related to the publication of this article.

\section{SOURCE OF FINANCING}

The study was conducted on the basis of the Cardiology Department of $t$ Kursk regional clinical hos-pital, Cardiology Department of $t$ Kursk city hospital of emergency medical care, 
KSMU. Additional sources of funding were not involved in the study.

\section{CONFORMITY WITH THE PRINCIPLES OF ETHICS}

The study protocol was approved by the Ethical Committee under Kursk state medical university (Protocol No. 7 of 07.09.2015), each of the patients signed the informed consent to articipate in the research.

Received 03.06.2019 Accepted 19.09.2019

For citation: Yakovleva M.V., Pribylov S.A., Pribylova N.N. Influence of inhibitors of angiotensin-converting enzyme, sartan and surgical revascularization on vascular wall stiffness in patients with coronary heart disease in combination with chronic kidney disease. Kursk Scientific and Practical Bulletin "Man and His Health". 2019; (3):12-19. DOI: 10.21626/vestnik/2019-3/02. 